\title{
Pacific Decadal Oscillation: Tropical Pacific Forcing versus Internal Variability
}

\author{
Yu ZHANG AND SHANG-PING XIE \\ Physical Oceanography Laboratory, Qingdao Collaborative Innovation Center of Marine Science and Technology, \\ Ocean University of China, and Qingdao National Laboratory for Marine Science and Technology, Qingdao, China, \\ and Scripps Institution of Oceanography, University of California, San Diego, La Jolla, California \\ YU KOSAKA \\ Research Center for Advanced Science and Technology, The University of Tokyo, Tokyo, Japan \\ JUN-CHAO YANG \\ Physical Oceanography Laboratory, Qingdao Collaborative Innovation Center of Marine Science and Technology, \\ Ocean University of China, and Qingdao National Laboratory for Marine Science and Technology, Qingdao, China
}

(Manuscript received 21 March 2018, in final form 8 August 2018)

\begin{abstract}
The Pacific decadal oscillation (PDO) is the leading mode of sea surface temperature (SST) variability over the North Pacific (north of $20^{\circ} \mathrm{N}$ ). Its South Pacific counterpart (south of $20^{\circ} \mathrm{S}$ ) is the South Pacific decadal oscillation (SPDO). The effects of tropical eastern Pacific (TEP) SST forcing and internal atmospheric variability are investigated for both the PDO and SPDO using a 10-member ensemble tropical Pacific pacemaker experiment. Each member is forced by the historical radiative forcing and observed SST anomalies in the TEP region. Outside the TEP region, the ocean and atmosphere are fully coupled and freely evolve. The TEPforced PDO (54\% variance) and SPDO (46\% variance) are correlated in time and exhibit a symmetric structure about the equator, driven by the Pacific-North American (PNA) and Pacific-South American teleconnections, respectively. The internal PDO resembles the TEP-forced component but is related to internal Aleutian low (AL) variability associated with the Northern Hemisphere annular mode and PNA pattern. The internal variability is locally enhanced by barotropic energy conversion in the westerly jet exit region around the Aleutians. By contrast, barotropic energy conversion is weak associated with the internal SPDO, resulting in weak geographical preference of sea level pressure variability. Therefore, the internal SPDO differs from the TEP-forced component, featuring SST anomalies along $\sim 60^{\circ} \mathrm{S}$ in association with the Southern Hemisphere annular mode. The limitations on isolating the internal component from observations are discussed. Specifically, internal PDO variability appears to contribute significantly to the North Pacific regime shift in the 1940 s.
\end{abstract}

\section{Introduction}

The Pacific decadal oscillation (PDO) is the leading mode of monthly sea surface temperature (SST) anomalies in the North Pacific (poleward of $20^{\circ} \mathrm{N}$ ) (Mantua et al. 1997; Zhang et al. 1997). It exhibits a horseshoe-like SST pattern, with anomalies of one sign in the KuroshioOyashio extension (KOE) region (Nakamura et al. 1997; Nonaka et al. 2006) and of the opposite sign along the west coast of North America. The PDO predominantly varies on decadal-to-multidecadal time scales (Minobe 1997, 1999). It impacts U.S. summertime hydrologic

Corresponding author: Yu Zhang, yuz347@ucsd.edu variability (Barlow et al. 2001), North Pacific marine ecosystems, fisheries, and global climate (Miller and Schneider 2000; Mantua and Hare 2002).

Numerous studies have investigated the PDO mechanisms. A recent consensus is that the PDO is not a single mode but a combination of multiple physical processes (Schneider and Cornuelle 2005; Newman et al. 2016). Newman et al. (2016) decomposed the PDO into two components: tropical Pacific remote forcing and local North Pacific variability, both of which are associated with atmospheric Aleutian low (AL) variability. The warm phase of El Niño-Southern Oscillation (ENSO) excites the Pacific-North American (PNA) pattern, extending across the North Pacific to North 
a) PDO (POGA, 25.3\%)

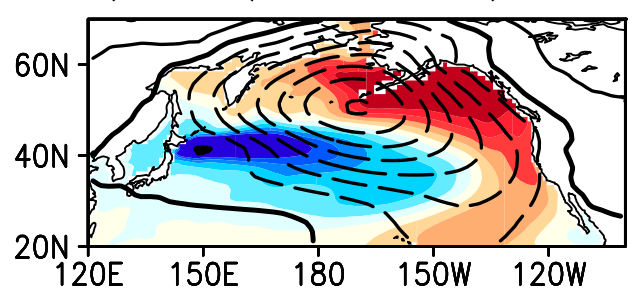

b) PDO (Obs, 29.9\%)

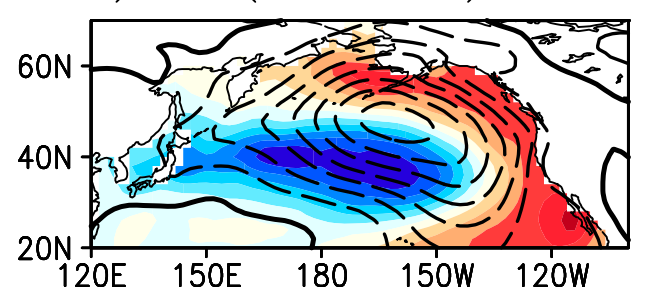

c) SPDO (POGA, 21.2\%)

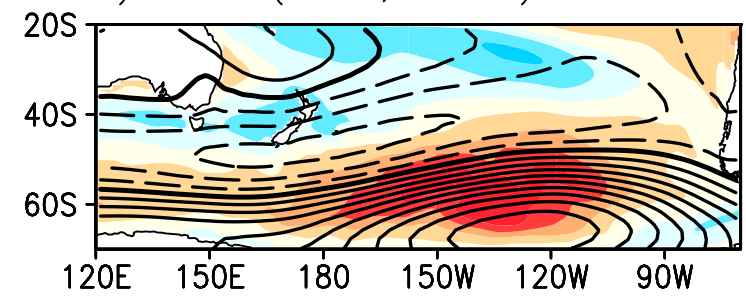

d) SPDO (Obs, 28.5\%)

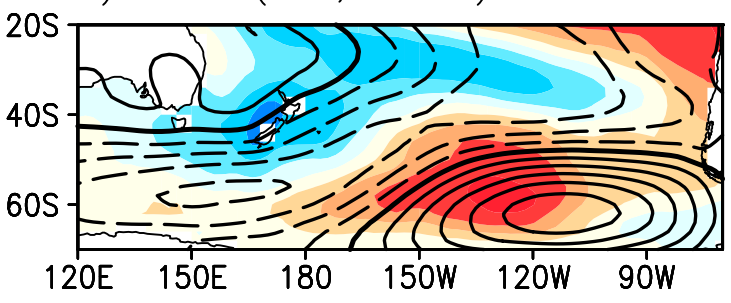

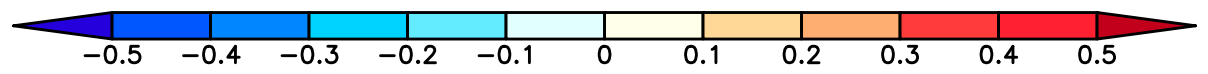

FIG. 1. Spatial patterns of the (a),(b) PDO and (c),(d) SPDO in POGA and observations. Patterns are the regressions of SST (shading; ${ }^{\circ} \mathrm{C}$ ) and SLP (contours with 0.2-hPa interval; zero line thickened) anomalies against the normalized PC1 of SST. (top) POGA and (bottom) observations. EOF in POGA is performed based on the tandem 10-member runs to derive one EOF pattern and corresponding $10 \mathrm{PC} 1 \mathrm{~s}$. The explained variance fraction is shown in parentheses in each panel based on annual means of July-June in the NH and January-December in the SH.

America with a center of action at the AL (Horel and Wallace 1981). The strengthened AL over the North Pacific drives the positive PDO pattern through surface heat fluxes, wind-driven mixing, and Ekman advection (Alexander et al. 2002). AL variability also originates from atmospheric internal dynamics, forcing a reddened ocean response (Frankignoul and Hasselmann 1977). SST in the KOE region can vary through dynamical adjustment of upper-ocean gyre circulations excited by anomalous wind stress curl. The SST changes in turn feed back to the atmosphere, forming a coupled oceanatmosphere process in the North Pacific (Zhang and Delworth 2015; Newman et al. 2016). Here we use a 10 -member ensemble of partially coupled simulations to separate tropical forced and internal components of the PDO. Each member run shares the common radiative forcing and prescribed tropical Pacific SST variability and differs only in the initial condition. Here internal variability refers to the deviations from the ensemble mean and is unrelated to tropical Pacific variability. This internal component includes not only the atmospheric internal variability but also the coupled air-sea interaction process discussed above.

The South Pacific counterpart of the PDO (poleward of $20^{\circ} \mathrm{S}$ ) is termed the South Pacific decadal oscillation (SPDO; e.g., Chen and Wallace 2015). The observed SPDO shows an equatorially symmetric SST structure with the PDO. Tropical Pacific forcing is suggested to be important for the SPDO (Shakun and Shaman 2009). The tropically excited Pacific-South American (PSA) pattern (Karoly 1989) is important in forcing the SPDO, mainly through the surface heat fluxes (Okumura 2013). It remains unclear if there is an SPDO component independent of tropical Pacific variability.

Previous studies have attempted to separate the PDO into tropical Pacific-forced and local internal variability components by means of statistical methods (e.g., Zhang et al. 1996; An and Wang 2005) and a hierarchy of coupled models. Ocean mixed layer models were used to study the ENSO-forced North Pacific variability, but they consider only thermodynamic coupling processes in the North Pacific (Alexander et al. 2002; Di Lorenzo et al. 2015). Partial coupling experiments were conducted to study the intrinsic North Pacific variability by prescribing the climatological SST in the tropics but with the ocean and atmosphere fully coupled in the extratropics (Zhang and Delworth 2015). Some studies investigated the impact of atmospheric noise on the North Pacific SST variability using an interactive ensemble coupling strategy (Kirtman and Shukla 2002; Yeh et al. 2007). Wang et al. (2012) compared the partial coupling experiment with a fully coupled run to investigate the influence of ENSO on the PDO. All the above studies have suggested that the PDO is made up of the tropical 
a) PDO spectrum

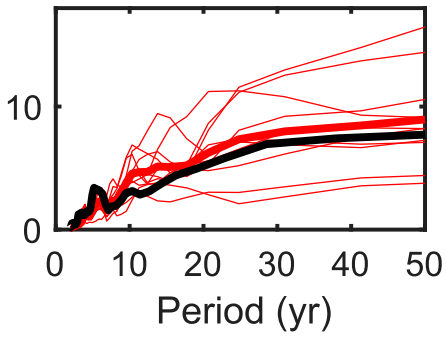

b) SPDO spectrum

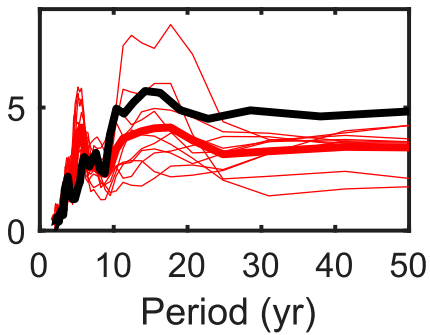

c) r(PDO, ENSO)

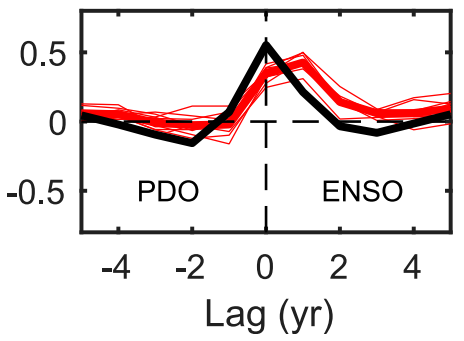

d) r(SPDO, ENSO)

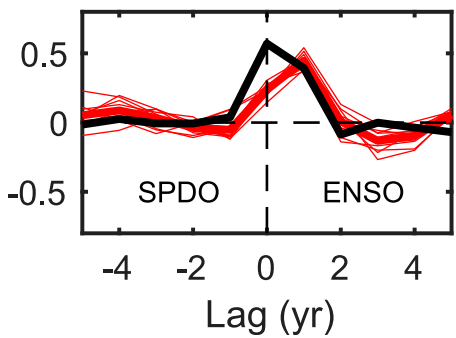

e) r(PDO, SPDO)

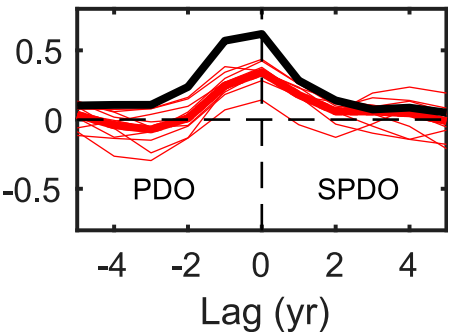

FIG. 2. Power spectra of the (a) PDO and (b) SPDO and cross correlations between the (c) PDO and ENSO, (d) SPDO and ENSO, and (e) PDO and SPDO. The ENSO index is winter SST anomalies (November-January mean for correlation with the PDO; June-August mean with the SPDO) averaged in the Niño-3.4 region $\left(5^{\circ} \mathrm{N}-5^{\circ} \mathrm{S}\right.$, $\left.170^{\circ}-120^{\circ} \mathrm{W}\right)$. Each thin red line denotes the analysis based on each run. The bold red lines denote the mean of the analyses of each run. Black lines denote observations. The texts labeled in (c)-(e) indicate that one leads the other [(e.g., "PDO" in (c) denotes that the PDO leads ENSO].

Pacific forced and intrinsic North Pacific components, both related to AL variability. However, not much attention has been given to possible differences in the atmospheric teleconnection pattern between the tropical forced and internal PDO. Even fewer studies examine the tropical-forced and internal components for the SPDO. It is unclear whether the SPDO components are similar in spatial structure to each other.

The present study uses a 10-member ensemble of the tropical Pacific pacemaker experiment (Kosaka and Xie 2016) to investigate the tropical eastern Pacific (TEP)forced and internal components of the PDO and SPDO, with a focus on the associated atmospheric teleconnection patterns. We identify distinct features between the TEP-forced and internal components of the SPDO. We suggest that the small degrees of freedom limit our ability to isolate the internal component from observations. The comparison with the pacemaker experiment indicates that the PDO regime shift in the 1940s (Minobe 1997,1999) is related to the internal variability.

The rest of the paper is organized as follows. Section 2 describes the pacemaker experiment, the method of isolating the TEP-forced and internal components, and the observational dataset used in this study. Section 3 compares the simulated PDO and SPDO variabilities by the pacemaker experiment with observations. Section 4 investigates the distinct characteristics between the
TEP-forced and internal components for both the PDO and SPDO. Furthermore, barotropic energy conversion is diagnosed for atmospheric anomalies to explain the similarity (distinction) of the two components for the PDO (SPDO). Section 5 discusses the limitations on isolating the internal component from observations and identifies the relative contribution of TEP-forced and internal components to the PDO regime shifts. Section 6 is a summary with some discussion.

\section{Data and methods}

A long-term tropical Pacific pacemaker experiment, named Pacific Ocean-Global Atmosphere (POGA) (Kosaka and Xie 2016), is used to isolate the TEP-forced and internal components based on the Geophysical Fluid Dynamics Laboratory Coupled Model, version 2.1 (CM2.1; Delworth et al. 2006). The POGA ensemble has 10 -member runs, each of which is forced by the identical historical radiative forcing and observed SST anomalies in the TEP domain (from $180^{\circ}$ to the American coast, $15^{\circ} \mathrm{S}-15^{\circ} \mathrm{N}$, with a $5^{\circ}$ buffer zone north, south, and west of the domain), but with different atmospheric and oceanic initial conditions. Outside the TEPrestoring region, the ocean and atmosphere are fully coupled and freely evolve. The horizontal resolution of the ocean is approximately $1^{\circ}$ longitude $\times 1^{\circ}$ latitude, 
a) TEP-forced PDO (46.1\%)

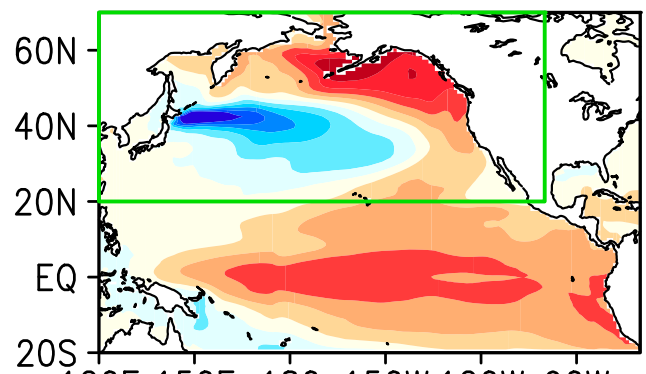

120E 150E 180 150W 120W 90W

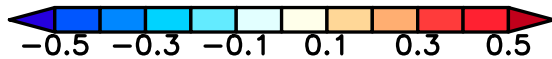

d) internal PDO (20\%)
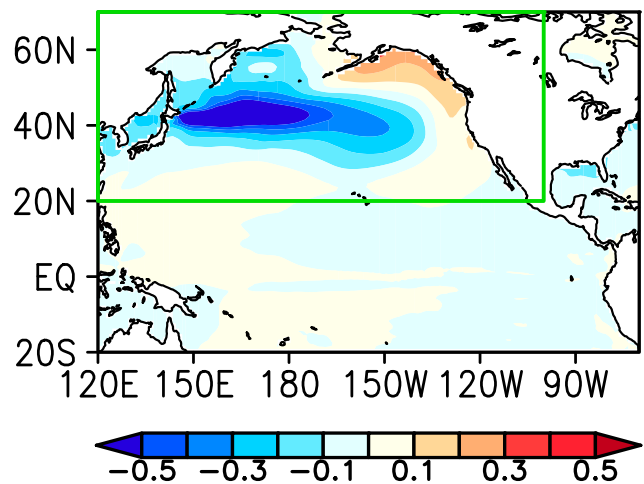

b) TEP-forced SLP

c) TEP-forced Z200
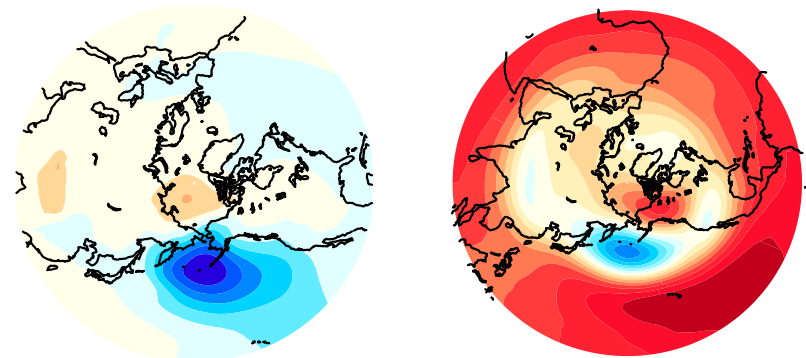

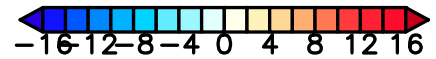

e) internal SLP

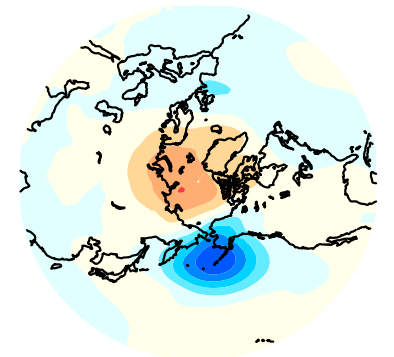

f) internal Z200

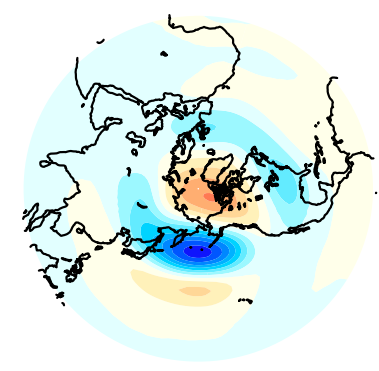

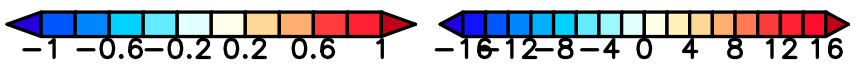

FIG. 3. TEP-forced and internal components of the PDO. Regression patterns of (a),(d) SST ( $\left.{ }^{\circ} \mathrm{C}\right)$; (b),(e) SLP (hPa); and (c),(f) Z200 (m) anomalies against the normalized PC1 of SST for both the TEP-forced and internal components. (top) TEP-forced and (bottom) internal components are indicated. The EOF domain is the North Pacific $\left(20^{\circ}-70^{\circ} \mathrm{N}, 120^{\circ} \mathrm{E}-100^{\circ} \mathrm{W}\right.$; green rectangular box $)$ based on the annual mean of July-June. Note that the EOF of internal SST is performed based on the tandem 10-member internal components to derive one EOF pattern and the corresponding $10 \mathrm{PC} 1 \mathrm{~s}$. The regression patterns of SLP (Z200) are shown poleward of $20^{\circ} \mathrm{N}$ (equator). The explained variance fraction for the TEP-forced and internal components are shown in parentheses in (a) and (d), respectively.

with finer meridional resolution equatorward of $30^{\circ} \mathrm{S}$ and $30^{\circ} \mathrm{N}\left(1 / 3^{\circ}\right.$ at the equator $)$. The atmospheric resolution is about $2.5^{\circ}$ longitude $\times 2^{\circ}$ latitude. The time period of $1890-2014$ is analyzed. We refer details on the model framework to Kosaka and Xie $(2013,2016)$.

To obtain the TEP-forced component, we calculate the ensemble mean of 10 POGA members and then subtract the ensemble mean of 20-member historical runs, each of which is forced by the historical and representative concentration pathway 4.5 (RCP4.5) radiative forcing and based on CM2.1, to remove the radiatively forced response. The internal component is obtained by subtracting the POGA ensemble mean from each POGA member. Note that the internal component here refers to variability independent of the prescribed TEP SST. Although 10 members may be not sufficient to extract the TEP-forced and internal components in a single event, the PDO and SPDO are obtained from empirical orthogonal function (EOF) analysis, which also exploits the degrees of freedom in the time dimension. Our analyses suggest that 10 members are sufficient for statistically isolating the TEP-forced and internal variability of the PDO and SPDO [see the strong (weak) connection of SST anomalies with the tropical Pacific in Figs. 3a and 5a (Figs. 3d and 5d)]. In addition to CM2.1 POGA, we also examine the POGA results based on the Community Earth System Model, version 1 (CESM POGA; Deser et al. 2017; see the appendix).

We use the Extended Reconstructed Sea Surface Temperature product, version 5 (ERSSTv5; Huang et al. 2017). Other SST datasets show similar results. The analysis period begins from 1900 (until 2014) because of large uncertainties in observations prior to the early twentieth century. We also use the Southern Oscillation index (SOI) from 1890 to 2014 to represent long-term tropical Pacific variability. This index is based on annual standardization, which has shown to maximize the signal of large-scale variability (Trenberth 1984). 


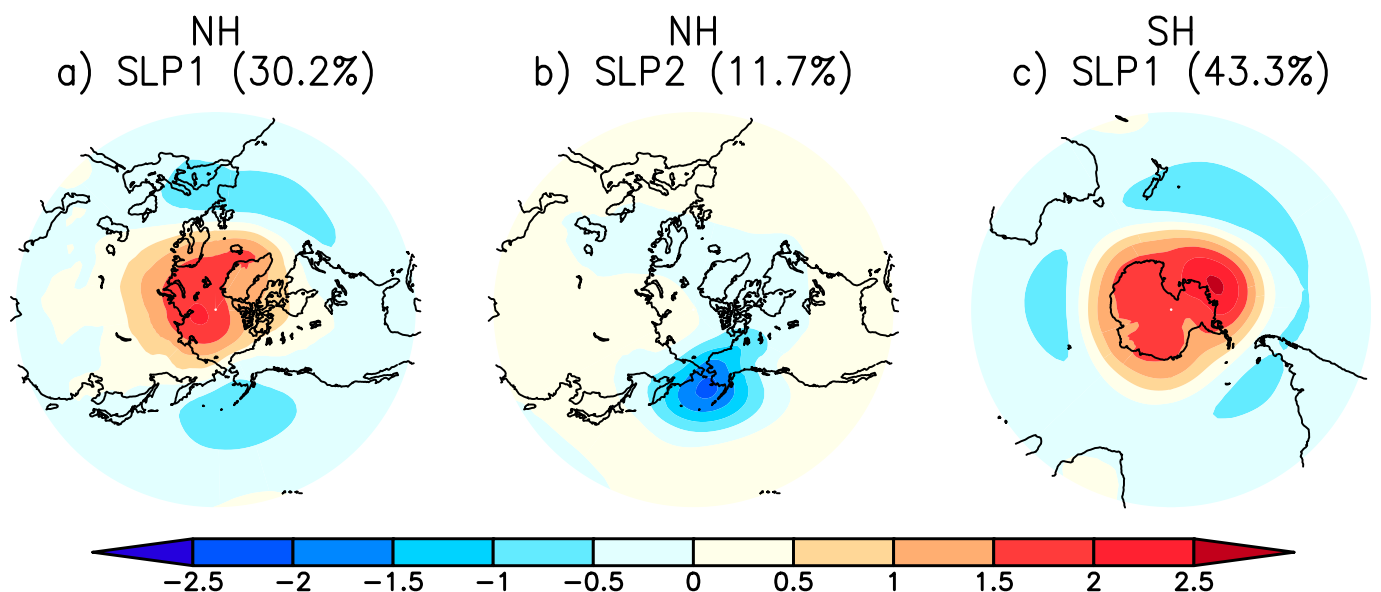

FIG. 4. Leading modes of hemispheric internal SLP variability. Regression patterns of internal SLP anomalies (hPa) against normalized internal (a) NH SLP PC1, (b) NH SLP PC2, and (c) SH SLP PC1. EOFs and regressions are performed poleward of $20^{\circ}$ latitude. The SLP associated with EOF1 and EOF2 are labeled as SLP1 and SLP2, respectively, based on annual means of July-June in the NH and January-December in the SH. The explained variance fraction is shown in parentheses in each panel.

We focus on the PDO and SPDO variabilities on interannual-to-multidecadal time scales. In the internal component, we subtract climatology in each ocean variable of each member to remove initial perturbations that persist throughout the integration in the Southern Ocean. The annual mean centered on the local wintertime is calculated, from July to the following June in the Northern Hemisphere (NH), and January-December in the Southern Hemisphere (SH). The reemergence process occurs in local winter and is important for the lowfrequency PDO and SPDO (Newman et al. 2003; Shakun and Shaman 2009).

To isolate the TEP-forced covariability mode, we conduct joint EOF analysis of annual-mean (July-June) SST anomalies between the North and South Pacific. The analyses based on the annual mean of JanuaryDecember are similar (not shown). SST anomalies are normalized by the spatially averaged SST standard deviation in each basin. This normalization method assigns equal weight on SST variability between the North and South Pacific.

\section{Evaluating POGA simulation}

We first evaluate the POGA's skill in simulating the spatial-temporal structures of the observed PDO and SPDO. Figure 1 shows the spatial patterns of the PDO and SPDO along with the corresponding SLP anomalies. In general, POGA well simulates the PDO, with a horseshoe-like SST pattern associated with strengthened AL variability, although some biases exist, such as a slight westward shift in the main center of the AL anomaly, stronger SST anomalies in the KOE region, and weaker SST anomalies in the subtropical northeastern Pacific (Fig. 1a vs Fig. 1b). POGA also well simulates the SPDO pattern, characterized by SST cooling below the South Pacific convergence zone (SPCZ) region and around New Zealand and SST warming in the southeastern South Pacific and Southern Ocean. It is associated with low pressure anomalies in the midlatitudes, with maxima south of New Zealand, and high pressure anomalies centered around $65^{\circ} \mathrm{S}$, $120^{\circ} \mathrm{W}$ (Fig. 1c vs Fig. 1d).

We further compare the temporal characteristics of the PDO and SPDO between POGA and observations (Fig. 2). Overall, POGA well simulates the PDO (Fig. 2a) and SPDO spectra (Fig. 2b), although the latter of which shows strong interannual and weak decadal-tomultidecadal variability. The model also captures the correlation between ENSO and the PDO or SPDO, albeit biased somewhat in lead/lag (Figs. 2c,d). The correlation between the PDO and SPDO in POGA is lower than in observations (Fig. 2e). This may arise from too strong internal variability in POGA (see further discussion in section 5a).

TABLE 1. Spatial correlations between the SLP patterns associated with the internal PDO and SPDO (Figs. 3e, 5e) and the corresponding internal SLP regression patterns in Fig. 4. The SH SLP2 is also included for computing the spatial correlation with the internal SPDO SLP (not shown in Fig. 4).

\begin{tabular}{lcc}
\hline \hline & Internal SLP1 & Internal SLP2 \\
\hline Internal PDO SLP & 0.89 & 0.53 \\
Internal SPDO SLP & 0.99 & 0.18 \\
\hline
\end{tabular}




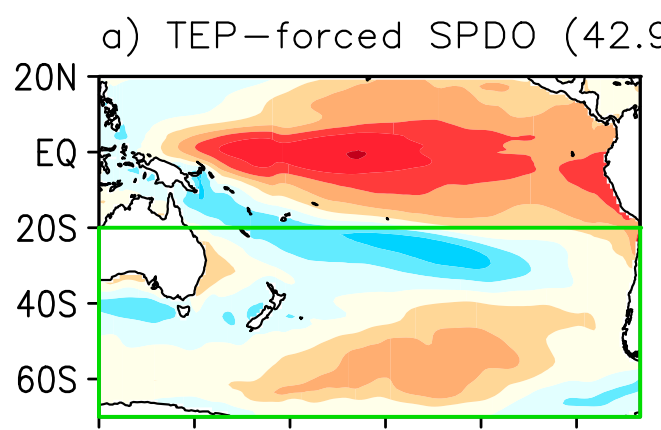

120E 150E 180 150W 120W 90W

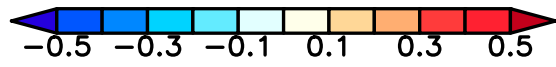

d) internal SPDO (17.6\%)
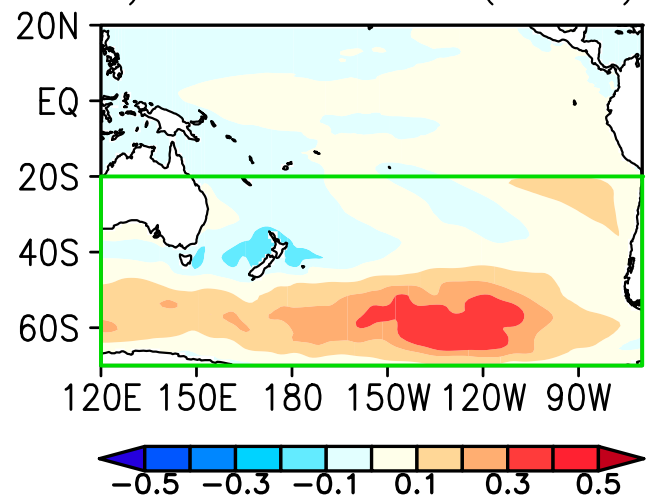

b) TEP-forced SLP
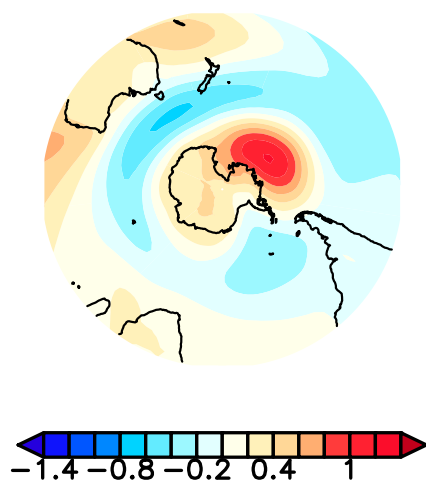

e) internal SLP
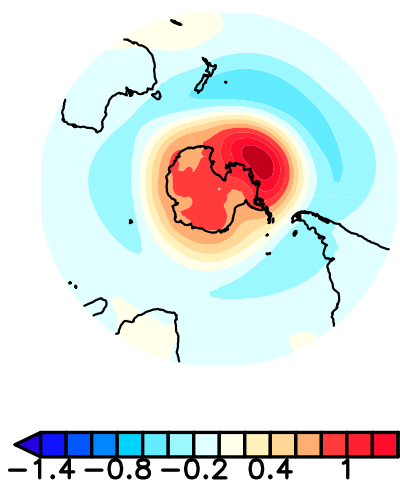

c) TEP-forced

Z200
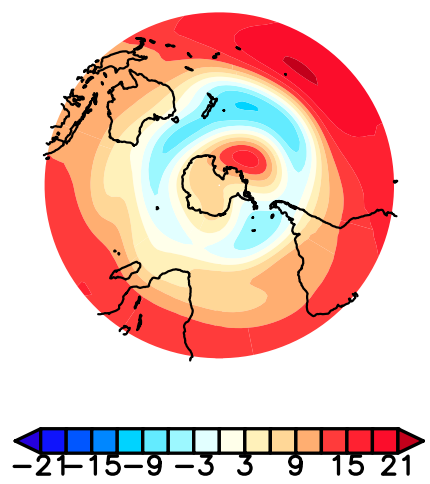

f) internal Z200
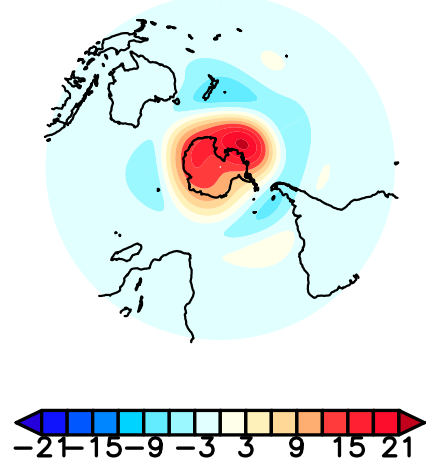

FIG. 5. As in Fig. 3, but for the SPDO. Based on the annual mean of January-December. The EOF domain is in the South Pacific $\left(70^{\circ}-20^{\circ}\right.$ S, $120^{\circ} \mathrm{E}-70^{\circ} \mathrm{W}$; green rectangular box).

Nevertheless, POGA well simulates both the spatial and temporal characteristics of the observed PDO and SPDO. Thus, we can further investigate the TEP-forced and internal components based on POGA.

\section{TEP-forced versus internal variability}

This section explores the characteristics of the TEPforced and internal components separately for the PDO and SPDO. We identify distinct spatial patterns between these two components, especially for the SPDO.

\section{a. $P D O$}

Figure 3 shows the TEP-forced and internal components of the PDO. Generally, both the TEP-forced and internal PDOs exhibit a horseshoe-like SST pattern in the North Pacific, although the internal component features strong SST cooling over the KOE region (Fig. 3a vs Fig. 3d). The TEP-forced PDO is closely related to the ENSO-like SST pattern in the tropics, while the internal PDO is confined to the extratropical North Pacific. Both the TEP-forced and internal PDOs are associated with the anomalous AL over the North $\mathrm{Pa}$ cific (Figs. 3b,e), consistent with previous findings (e.g., Newman et al. 2016). However, these two components are related to different $\mathrm{NH}$ atmospheric teleconnections. The TEP-forced PDO is driven by the PNA pattern (Wallace and Gutzler 1981) excited from the tropical Pacific (Fig. 3c), which differs from the tropical/Northern Hemisphere pattern in Barnston and Livezey (1987). From the SLP field, the internal PDO is not only associated with the anomalous AL, but also with an anomalously high SLP system over the Arctic polar cap region (Fig. 3e). This SLP pattern is reminiscent of the negative phase of the Northern Hemisphere annular mode (NAM), with the center of action over the entire Arctic Ocean surrounded by a zonal ring of the opposite sign centered near $45^{\circ} \mathrm{N}$ (Thompson and Wallace 1998, 2000). From the 200-hPa geopotential height (Z200) anomaly pattern, the internal PDO appears to be a hybrid of the NAM and PNA pattern (Fig. 3f).

To examine whether the atmospheric teleconnection patterns associated with the internal PDO are the 
a) TEP-forced PDO

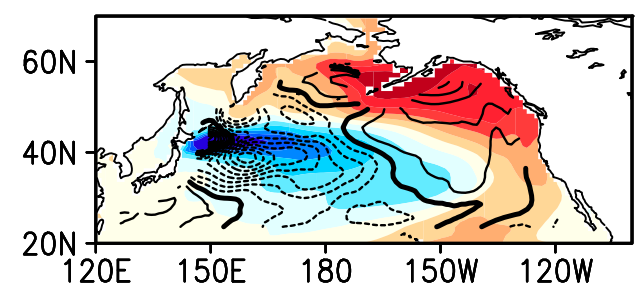

b) internal PDO

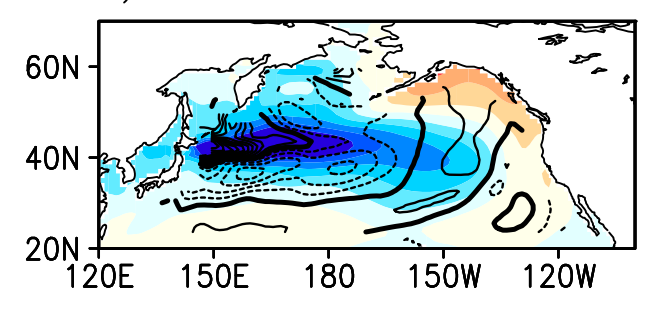

c) TEP-forced SPDO

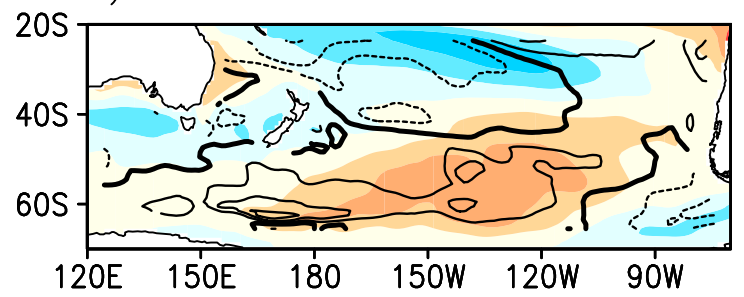

d) internal SPDO

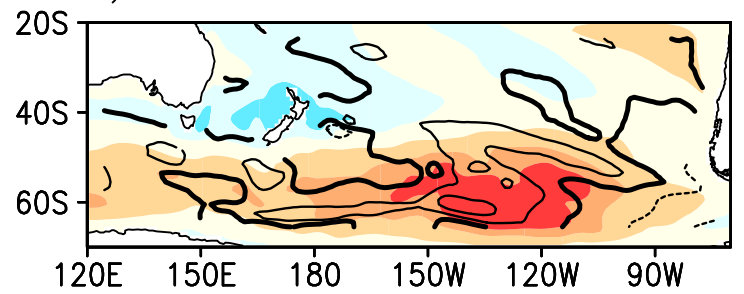

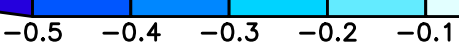

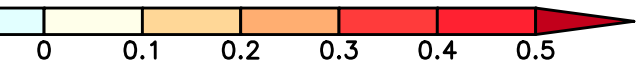

FIG. 6. The 1-yr-lead regressions of the sum of surface turbulent heat flux (latent and sensible heat fluxes) and ocean Ekman advection anomalies (contours with $1 \mathrm{~W} \mathrm{~m}^{-2}$ interval; positive downward; zero line thickened) against PC1s of the (a),(b) PDO and (c),(d) SPDO. (top) TEP-forced and (bottom) internal components. Simultaneous SST anomalies $\left({ }^{\circ} \mathrm{C}\right.$ ) regressed onto PDO (Figs. 3a,d) and SPDO (Figs. 5a,d) are superimposed as shadings.

dominant modes of internal atmospheric circulation in the $\mathrm{NH}$, we obtain EOFs of the internal component of the annual-mean (July-June) SLP anomalies poleward of $20^{\circ} \mathrm{N}$. Figures $4 \mathrm{a}$ and $4 \mathrm{~b}$ show the regressions of SLP anomalies against the normalized principal components (PCs). The first EOF (SLP1) is the NAM (Fig. 4a), and the second EOF (SLP2) shows an anomalously low pressure over the Aleutian Islands (Fig. 4b). The SLP2 corresponds to the PNA pattern, which is the second EOF mode of the $\mathrm{NH}$ atmospheric circulation anomaly in observations, as reported by Wallace and Thompson (2002). Spatial correlations of SLP1 and SLP2 with the SLP pattern related to the internal PDO (Fig. 3e) demonstrate that the internal PDO is primarily associated with the internal NAM teleconnection, and secondarily with the internal PNA teleconnection (Table 1).

\section{b. $S P D O$}

Figure 5 shows the TEP-forced and internal components of the SPDO. The TEP-forced SPDO connects to the ENSO-like variability and exhibits a rather symmetric structure about the equator with the TEP-forced PDO (Figs. 3a, 5a). It is characterized by an SST cooling below the SPCZ region surrounded by SST warming on both the equatorward and poleward sides (Fig. 5a). Analogous to the TEP-forced PDO, the TEP-forced SPDO is driven by the PSA pattern (Mo and Ghil 1987) excited from the tropical Pacific (Figs. 5b,c).
The internal SPDO is very different from the TEPforced counterpart (Fig. 5a vs Fig. 5d). Notably, the internal SPDO exhibits strong SST warming along $\sim 60^{\circ} \mathrm{S}$ with weak cooling around New Zealand, but without the cooling in the SPCZ region (Fig. 5d). The internal SPDO is not associated with the PSA pattern but with the Southern Hemisphere annular mode (SAM), which features a primary center of action over Antarctica that is regionally enhanced over the Amundsen Sea and western Antarctica, accompanied by a zonal ring of opposite sign along $\sim 45^{\circ} \mathrm{S}$ (Figs. $5 \mathrm{e}, \mathrm{f}$ ) (Thompson and Wallace 2000). The SAM is the leading mode of internal SLP variability in the SH winter (Fig. 4c). High spatial correlation with the internal SAM (Fig. 5e) indicates a strong association with the internal SPDO (Table 1).

We evaluate the TEP-forced and internal components by projecting POGA anomalies onto the PDO (Fig. 1a) and SPDO (Fig. 1c) patterns. The variance of the PDO and SPDO explained by TEP forcing is $54 \%$ and $46 \%$, respectively. This result suggests that both the TEPforced and internal components are important for the PDO and SPDO variability.

\section{c. Atmospheric forcing of the PDO and SPDO}

This subsection examines the mechanism for SST variability in the PDO and SPDO. As both surface turbulent heat flux and ocean Ekman advection are related to surface wind variability, we perform 1-yr-lead 


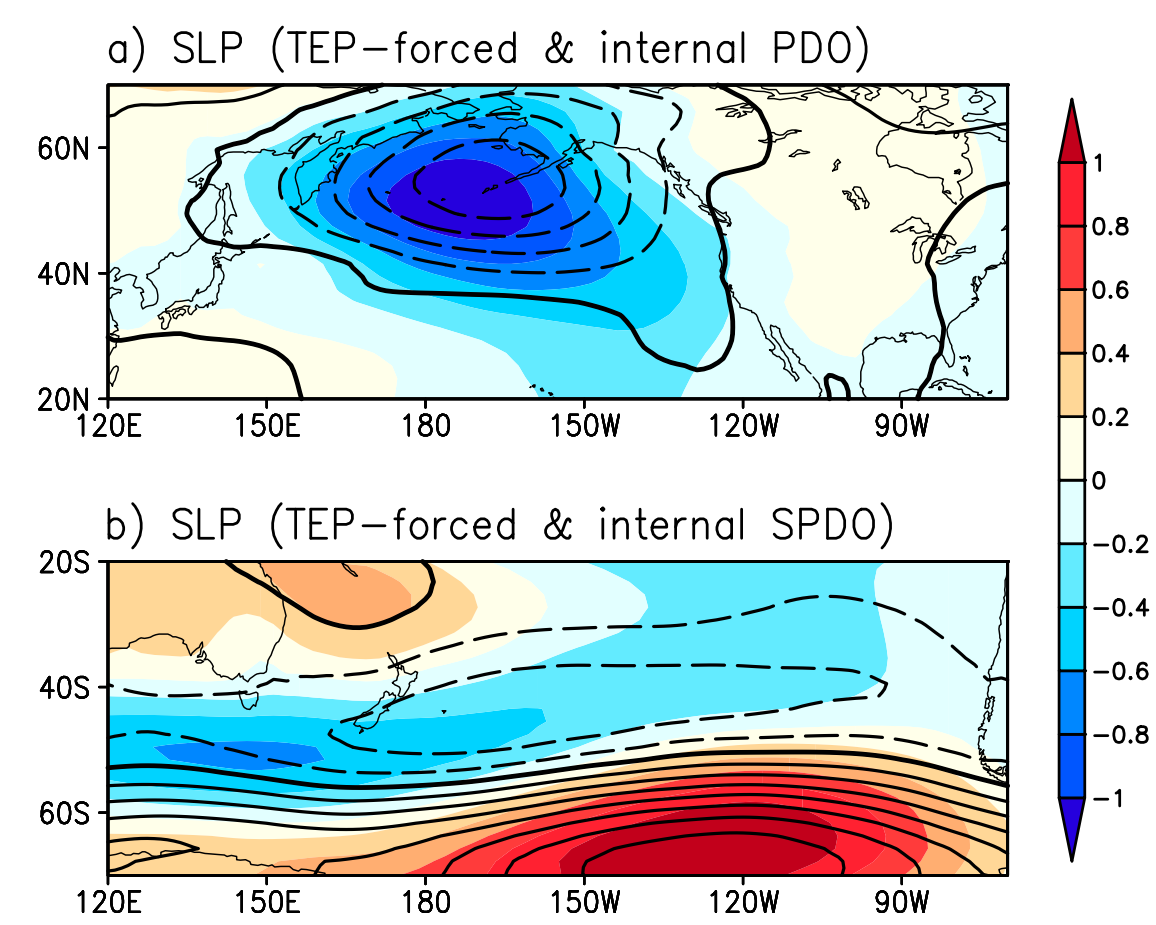

FIG. 7. TEP-forced (shading; hPa) and internal (contours with 0.2 -hPa interval; zero line thickened) components of the SLP pattern associated with the (a) PDO and (b) SPDO. SLP patterns in (a) are from Figs. 3b and $3 e$ in the North Pacific and those in (b) are from Figs. 5b and $5 \mathrm{e}$ in the South Pacific.

regressions of the sum of these two terms against PC1s of the PDO and SPDO (contours in Fig. 6). Ekman advection is given by $c / f(\mathbf{k} \times \boldsymbol{\tau}) \cdot \nabla \mathrm{SST}$, where $c$ is the specific heat of seawater, $f$ is the Coriolis parameter, $\mathbf{k}$ is the unit normal vector, and $\tau$ is the surface wind stress that is converted from the surface wind using quadratic stress law. Our calculation suggests that the Ekman advection is weak compared to heat flux. Thus, Fig. 6 can be mainly regarded as the surface heat flux effect.

For both the TEP-forced and internal PDOs (Figs. 6a,b), the overall SST pattern is consistent with surface heat flux forcing and Ekman advection. In the KOE, surface heat flux and Ekman advection damp SST anomalies, indicating that ocean dynamics plays a primary role. In the central-to-eastern North Pacific on the boundary between the SST cooling and warming regions, vertical entrainment due to the intensified wind speed (not shown) might also contribute to the SST cooling. For the TEP-forced and internal SPDOs (Figs. 6c,d), SST anomalies are basically driven by the PSA pattern and SAM, respectively. Thus, SST anomalies in the open ocean are driven by atmospheric wind variability through surface processes (heat flux and Ekman advection). In section 4d, we address the question of why the atmospheric circulation patterns associated with the TEP-forced and internal SPDOs are distinct but similar for the PDOs.

\section{d. Barotropic energy conversion}

For the PDO, both components are related to similar AL anomaly patterns in SLP (Fig. 7a). The SLP anomalies in the midlatitudes associated with the TEP-forced SPDO are geographically anchored south of Australia (negative value of shading in Fig. 7b). However, there is no geographical preference for SLP pattern in the midlatitudes associated with the internal SPDO (negative value of contour in Fig. 7b).

Over the North Pacific, previous studies suggested that the stationary AL variability is due partly to barotropic energy conversion (Simmons et al. 1983; Trenberth et al. 1998). It refers to a process through which disturbances can gain kinetic energy from the climatological zonally varying flow. This preferentially occurs in the westerly jet exit region as west of the Aleutians. Here we calculate the local barotropic energy conversion (CK) associated with the internal PDO and SPDO in Cartesian coordinates, following the formulation (cf. Simmons et al. 1983):

$$
\mathrm{CK}=-\left(u^{2}-v^{\prime 2}\right) \frac{\partial \bar{u}}{\partial x}-u^{\prime} v^{\prime} \frac{\partial \bar{u}}{\partial y} .
$$

Here $\bar{u}$ is the zonal velocity of the basic state; and $u^{\prime}$ and $v^{\prime}$ are the zonal and meridional velocity anomalies, 


\section{a) CK, Z200 (internal PDO)}

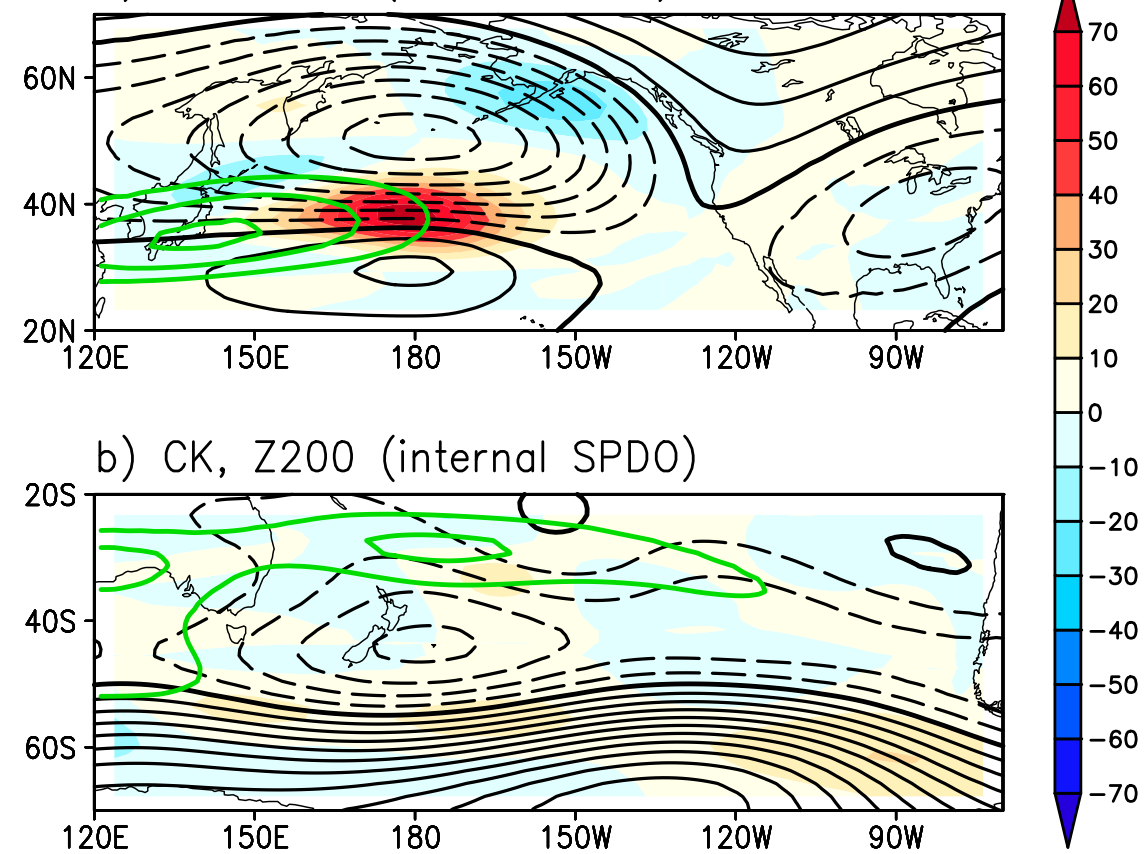

FIG. 8. The CK patterns (shading; $\times 10^{-7} \mathrm{~m}^{2} \mathrm{~s}^{-3}$ ) associated with the (a) internal PDO and (b) internal SPDO. Green contours denote climatology of annual mean (July-June in the NH; January-December in the SH) zonal wind (contours with $5 \mathrm{~m} \mathrm{~s}^{-1}$ interval; only $\geq 30 \mathrm{~m} \mathrm{~s}^{-1}$ are shown). Z200 patterns (black contours with 2-m interval; zero line thickened) in (a) are from Fig. $3 f$ in the North Pacific and in (b) are from Fig. $5 f$ in the South Pacific.

respectively, which are obtained by regression against normalized PC1 of the internal PDO or SPDO. Positive $\mathrm{CK}$ indicates the conversion of kinetic energy from the mean flow to atmospheric circulation perturbations. The calculation is based on the wintertime-centered annual mean at the 200-hPa level.

Over the North Pacific, positive CK is large in the westerly jet exit region (Fig. 8a), indicating that strong barotropic energy conversion anchors AL variability, which in turn induces the internal PDO. Because the AL anomaly pattern is similar, the TEP-forced and internal components of the PDO both feature a horseshoe-like SST pattern (Figs. 3a,d). By contrast, CK over the South Pacific is weak despite a comparable magnitude of the circulation anomaly (Fig. 8b), resulting in a weak zonal preference for the atmospheric circulation anomaly associated with the internal SPDO. Consequently, the internal SPDO features pronounced SST warming along $\sim 60^{\circ} \mathrm{S}$, associated with the negative phase of the atmospheric internal SAM (Figs. 5d-f). The TEP-forced component shows strong zonal variations, with low SLP anomalies of the PSA pattern (shading in Fig. 7b) driving the SST cooling in the SPCZ region and SST warming in the northeast-southwest direction on the poleward side (Fig. 5a).
Ultimately, the westerly jets vary more strongly in the Northern than in the Southern Hemisphere. The resultant interhemispheric difference in barotropic energy conversion explains why the internal PDO resembles the TEP-forced component while the two components of the SPDO are markedly distinct. The results based on the CESM POGA are similar (see the appendix).

\section{Discussion: Observed internal variability}

\section{a. Limitations on isolating the internal component}

In the POGA ensemble mean, the temporal correlation is moderate between the PDO and SPDO (Table 2). This could be because they are sensitive to details in the structure and seasonality of TEP SST or because of remaining internal variability in the 10-member average. Alternatively, we can perform joint SST EOF between the North and South Pacific (see the method in section 2). The leading PC captures interhemispheric coherent variability and is highly correlated with both the TEP-forced PDO and SPDO (Table 2). This leading EOF resembles the so-called interdecadal Pacific oscillation (IPO; Power et al. 1999; Henley et al. 2015). 
TABLE 2. Correlation coefficients among the PC1s of the PDO, SPDO, and joint EOF of annual mean (July-June) SST anomalies in the POGA ensemble mean. Correlations among the 10 -yr lowpass-filtered PC1s are listed in parentheses.

\begin{tabular}{lccc}
\hline \hline & PDO & SPDO & Joint PC1 \\
\hline PDO & - & - & - \\
SPDO & $0.60(0.57)$ & - & - \\
Joint PC1 & $0.82(0.85)$ & $0.94(0.91)$ & - \\
\hline
\end{tabular}

We apply the joint EOF method over the extratropical North and South Pacific basins to observations. Figure 9 shows the regressions of annual-mean (July-June) SST anomalies against the PCs of joint EOF, along with the POGA ensemble mean results. The results based on the January-December mean are similar (not shown). The joint EOF1 is highly correlated spatially and temporally between observations and the POGA ensemble mean (Figs. 9a and 9d; Table 3). This mode explains $38 \%$ and $24 \%$ of the variance in the POGA ensemble mean and observations, respectively. The second and higher modes disagree in spatial pattern between the POGA ensemble mean and observations (Figs. 9b,c vs Figs. 9e,f), indicating a limitation on reliably isolating higher modes by removing the TEP-forced variability over the North and South Pacific due to the small degrees of freedom in the instrumental record.

By design, POGA does not address the origin of TEP variability. The extratropical anomalies propagating toward the tropical Pacific are eventually restored by the observed TEP SST anomalies. The internal component might induce the TEP variability via the tropicalextratropical interactions. For example, the extratropical Pacific meridional mode can propagate into the

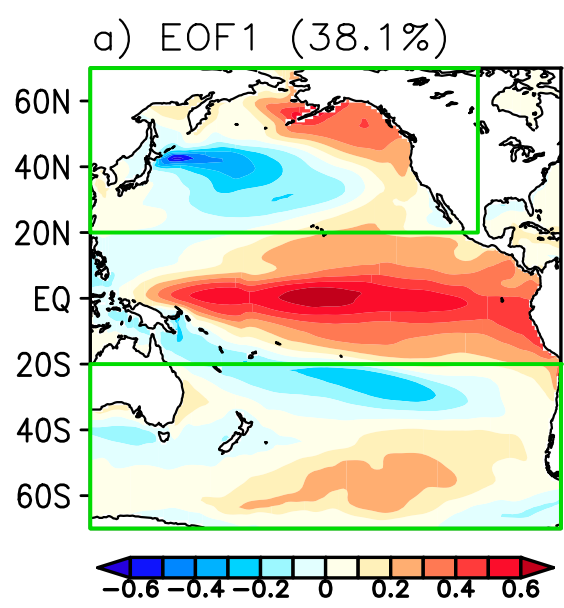

b) EOF2 (13.4\%)

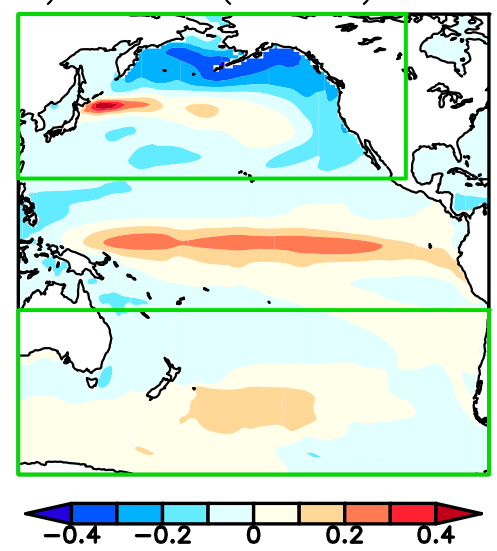

d) EOF1 (24.1\%)

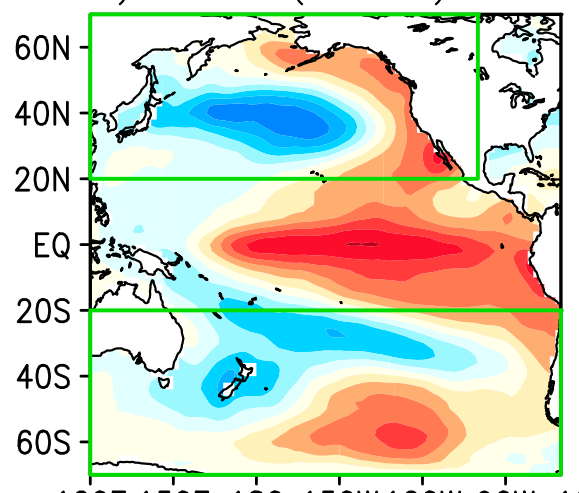

e) EOF2 (9.5\%)

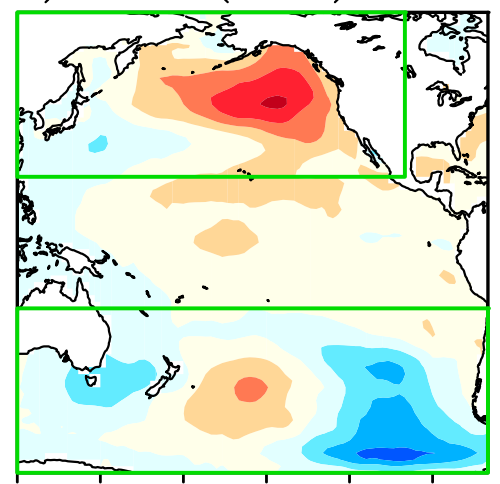

c) EOF3 (5.3\%)

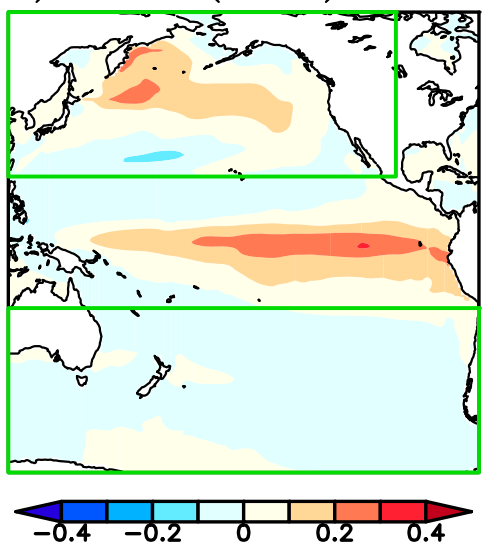

f) $\operatorname{EOF3}(7.7 \%)$

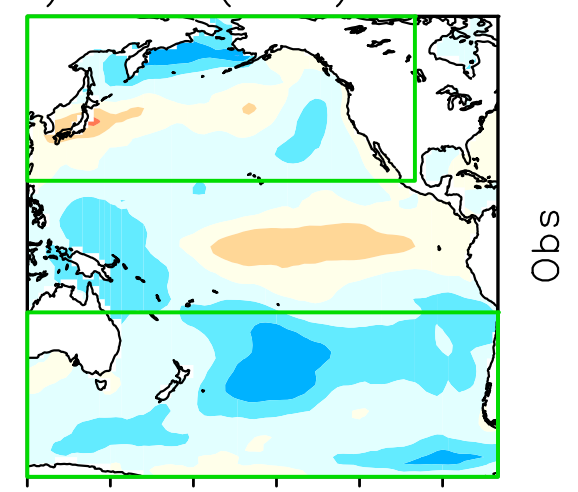

৫্য

@

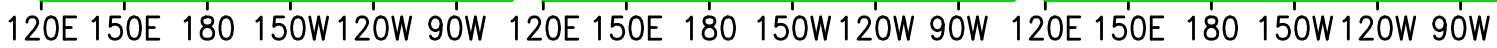
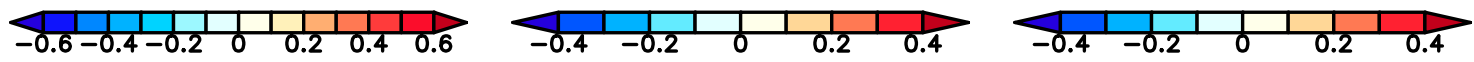

FIG. 9. Regressions of annual-mean (July-June) SST anomalies $\left({ }^{\circ} \mathrm{C}\right)$ in the (a)-(c) POGA ensemble mean and (d)-(f) observations against their individual PC1, PC2, and PC3 of the joint SST EOF. Joint EOF domains are in the North and South Pacific (green rectangular boxes). The explained variance of the total variance for the POGA ensemble mean and observations are listed in parentheses in each panel. 
TABLE 3. Correlation coefficients of the regression patterns in Fig. 9 and the PCs (parentheses) of the joint EOF between the POGA ensemble mean and ERSSTv5. "Reg" denotes the regression pattern.

\begin{tabular}{lccc}
\hline $\begin{array}{c}\text { POGA ensemble } \\
\text { mean obs }\end{array}$ & $\begin{array}{l}\text { Reg 1 } \\
\text { (PC1) }\end{array}$ & $\begin{array}{l}\text { Reg 2 } \\
\text { (PC2) }\end{array}$ & \multicolumn{1}{c}{$\begin{array}{l}\text { Reg 3 } \\
\text { (PC3) }\end{array}$} \\
\hline Reg 1 (PC1) & $0.86(0.69)$ & $0.27(0.07)$ & $0.34(0.04)$ \\
Reg 2 (PC2) & $0.23(0.13)$ & $-0.04(0.21)$ & $0.44(-0.22)$ \\
Reg 3 (PC3) & $0.42(0.23)$ & $0.31(0.17)$ & $0.53(-0.11)$ \\
\hline
\end{tabular}

tropics via the seasonal footprinting mechanism (Vimont et al. 2001, 2003; Di Lorenzo et al. 2015; Ma et al. 2017). The South Pacific is suggested to be coupled with the tropical Pacific on decadal time scales via the oceanic tunnel (Luo and Yamagata 2001). Okumura (2013) pointed out that atmospheric internal variability over the subtropical South Pacific can thermodynamically force the tropical Pacific.

\section{b. PDO regime shifts}

The PDO features marked regime shifts in the 1940s, the late 1970s, and the late 1990s (Minobe 1997, 1999). The joint EOF1 of the POGA ensemble mean suggests that the covariability between the PDO and SPDO is dominated by TEP forcing (Fig. 9a). Indeed, temporal correlation between the internal PDO and SPDO is nearly zero $(r=-0.01)$. In observations, the PDO and SPDO exhibit strong covariability in the late 1970s and 1990s, and the POGA ensemble mean captures these regime shifts (Figs. 10a, A3a). This suggests that the 1970s and 1990s regime shifts are dominated by TEP forcing, consistent with previous analyses (e.g., Nitta and Yamada 1989; Kosaka and Xie 2016). By contrast, the PDO-SPDO covariability is weak during the 1940s regime shift (black line in Fig. 10a vs Fig. 10b). The PDO exhibits a regime shift but the POGA ensemble mean fails to capture it (Figs. 10a, A3a). As a caveat, the TEP SST itself is somewhat uncertain during World War II because of sparse observations (Thompson et al. 2008) as discussed in Kosaka and Xie (2016). The SOI, which reflects large-scale tropical Pacific variability, exhibits a consistent phase shift with the PDO, but over a much shorter period (Fig. 10a). This suggests that the internal variability plays an important role in the 1940s regime shift of the PDO.

\section{Summary}

We have used a 10-member ensemble of a long-term tropical Pacific pacemaker experiment and showed that the TEP-forced and internal components are distinct for both the PDO and SPDO. The TEP-forced PDO and SPDO exhibit an interhemispherically symmetric structure

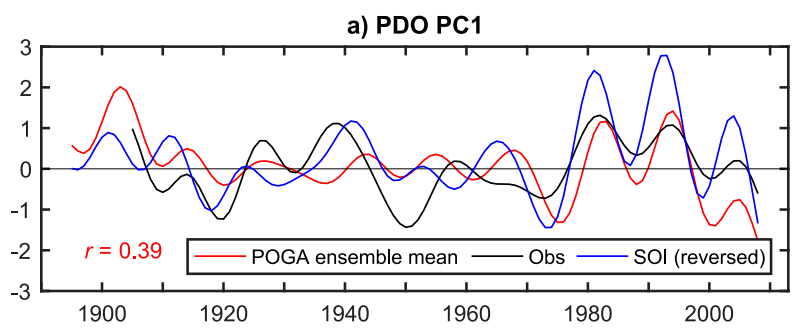

b) SPDO PC1

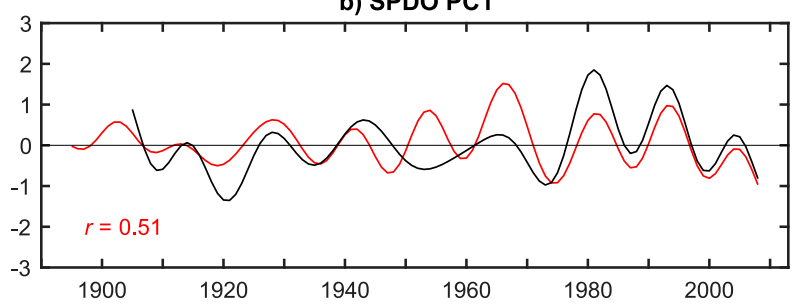

FIG. 10. The 10-yr low-pass-filtered annual-mean (a) PDO PC1 and (b) SPDO PC1 in the POGA ensemble mean (red) and observations (black). The 10-yr low-pass-filtered annual-mean (JulyJune) SOI (normalized; sign reversed) is superimposed in (a). The correlation coefficient of the 10-yr low-pass-filtered PC1 between the POGA ensemble mean and observations is marked in the bottom left in each panel.

about the equator, forced by the PNA and PSA patterns excited from the tropical Pacific, respectively. The internal PDO resembles the TEP-forced component but is related to internal AL variability associated with the NAM and PNA pattern. The internal variability is locally enhanced by barotropic energy conversion in the westerly jet exit region around the Aleutians, driving a horseshoe-like SST pattern similar to the TEP-forced PDO. By contrast, barotropic energy conversion is rather weak and ineffective to form the preferred spatial pattern associated with the internal SPDO, resulting in weak geographical preference of SLP variability. The resultant SST anomaly pattern differs from the TEP-forced SPDO, featuring pronounced SST variability along $\sim 60^{\circ} \mathrm{S}$ in association with the SAM teleconnection. These atmospheric patterns associated with the internal PDO and SPDO are the dominant modes of the internal atmospheric variability in each hemisphere. The more efficient barotropic energy conversion over the North than South Pacific explains why the internal PDO resembles the TEP-forced component while the internal and TEP-forced SPDOs are markedly distinct. The internal variability in the PDO appears to contribute significantly to the North Pacific climate regime shift in the 1940s, although short observations limit the confidence in the attribution.

As discussed in the introduction, coupled oceanatmosphere interaction could be important for the PDO. The atmospheric resolution of CM2.1 is insufficient to adequately represent the crucial mesoscale ocean-atmosphere interaction in the $\mathrm{KOE}$ region 
a) TEP-forced PDO (55.1\%)

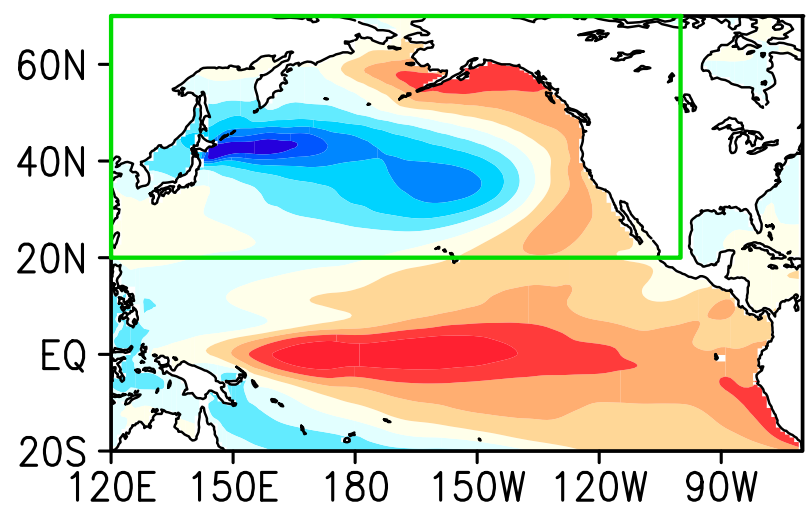

c) internal PDO (19\%)
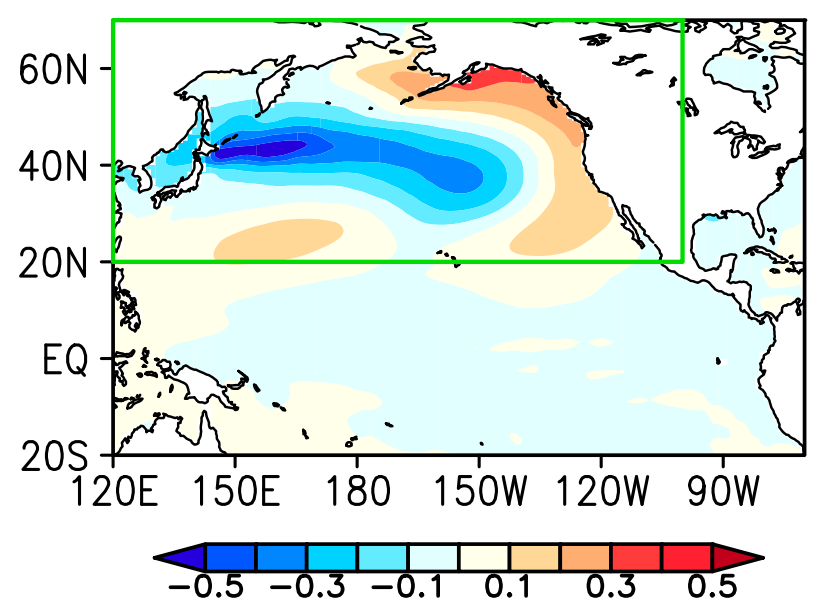

b) TEP-forced SLP

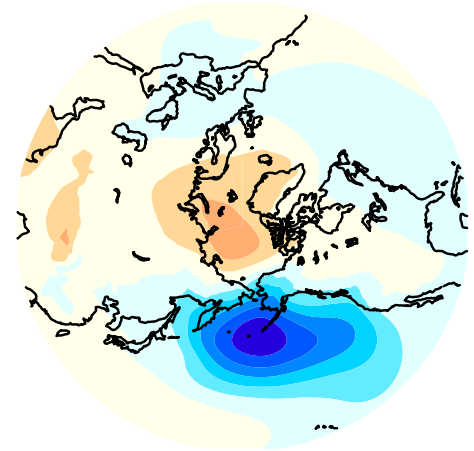

d) internal SLP
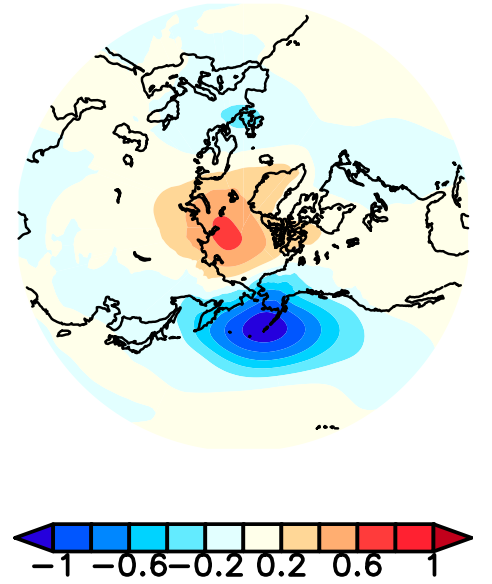

FIG. A1. As in Fig. 3, but for the CESM POGA. The regression patterns of Z200 field are omitted. Note that the internal PDO in CESM POGA is extracted as in the second EOF mode.

(Ma et al. 2016). Future research needs to examine detailed physical processes of the PDO and SPDO-both the TEP-forced and internal components-with higherresolution POGA experiments.

Acknowledgments. The ERSST, version 5, product is provided by the NOAA/Earth System Research Laboratory (www.esrl.noaa.gov/psd/data/gridded/data.noaa. ersst.v5.html), and the SOI time series is provided by Climate and Global Dynamics Division, NCAR (www. cgd.ucar.edu/cas/catalog/climind/soiAnnual.html). CESM1 historical, RCP8.5, and POGA runs have been obtained from the Earth System Grid (www.earthsystemgrid.org). We sincerely thank the three anonymous reviewers for their constructive comments and suggestions. This work is supported by the Natural Science Foundation of China (41490640 and 41490641), China Scholarship Council (201706330016), U.S. National Science Foundation (AGS 1637450), Japanese Ministry of Education,
Culture, Sports, Science and Technology (the Integrated Research Program for Advancing Climate Models and Arctic Challenge for Sustainability), the Japan Society for the Promotion of Science (15H05466 and 18H01278), and the Japan Science and Technology Agency (Belmont Forum CRA "InterDec").

\section{APPENDIX}

\section{The TEP-Forced and Internal Components of the PDO and SPDO in CESM POGA}

We also use 10-member runs of CESM POGA to investigate the characteristics of the TEP-forced and internal components of the PDO and SPDO. The prescribed SST dataset is identical to that in CM2.1 POGA. The horizontal resolutions of both atmosphere and ocean are approximately $1^{\circ}$ longitude $\times 1^{\circ}$ latitude. The time period of the experiment is from 1920 to 2013. 


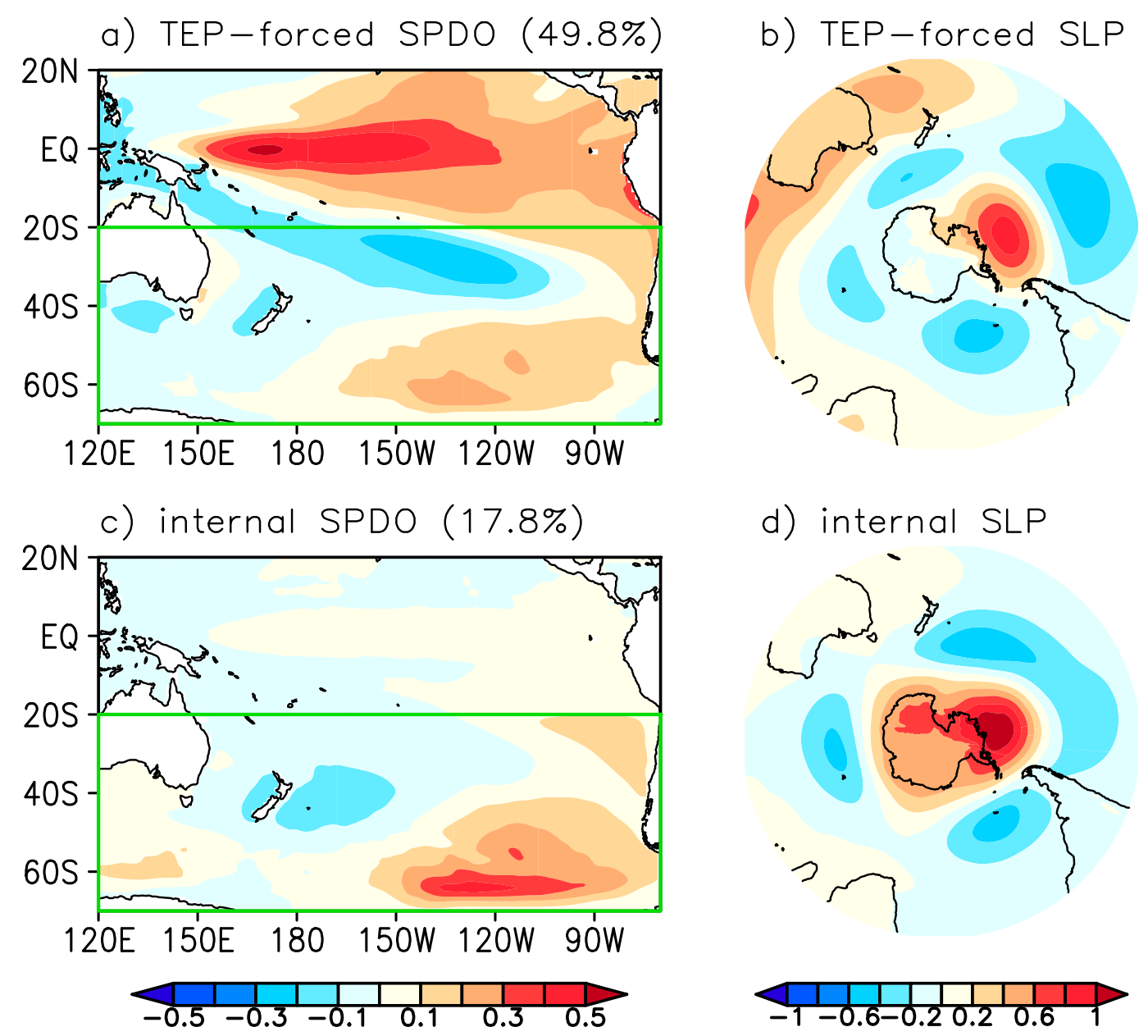

FIG. A2. As in Fig. A1, but for the SPDO.

We use CESM 40-member historical and RCP8.5 runs to remove the response to the radiative forcing.

Both the TEP-forced and internal PDOs exhibit similar horseshoe-like SST patterns and are associated with AL variability (Fig. A1), consistent with the results based on the CM2.1 POGA. The TEP-forced SPDO is also characterized by an interhemispherically symmetric SST pattern with the TEP-forced PDO and is driven by the PSA pattern (Figs. A2a,b). As in CM2.1, the internal SPDO in CESM1 markedly differs from the TEP-forced SPDO, without SST cooling in the SPCZ region (Fig. A2c) and is also associated with the zonally symmetric SAM teleconnection (Fig. A2d). Likewise, the internal SPDO is notably distinct from the TEP-forced SPDO, associated with little geographical preference of SLP anomalies because of the weak barotropic energy conversion. Regarding the observed PDO regime shifts, the CESM POGA ensemble mean captures the late 1970s and 1990s regime shifts but not the one in the
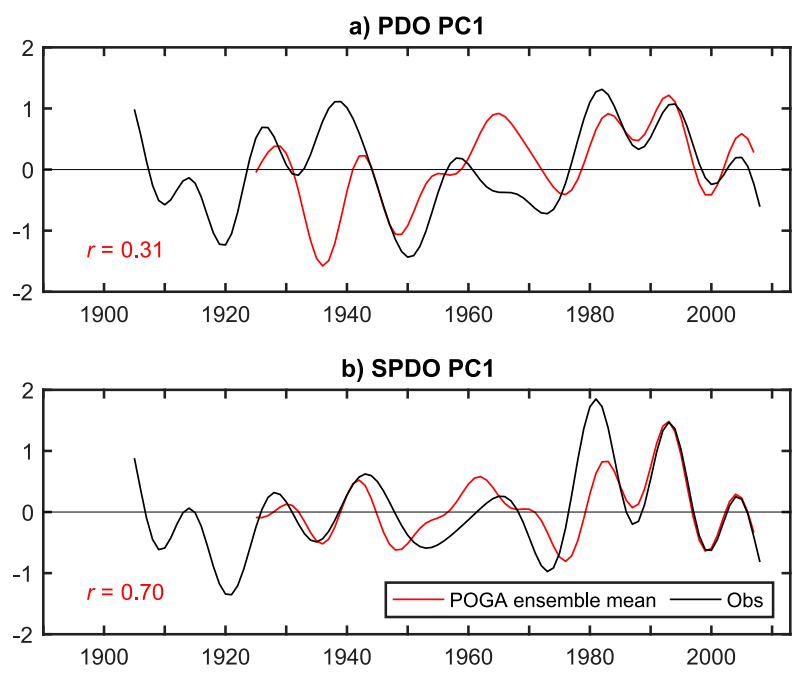

FIG. A3. As in Fig. 10, but for the comparison of the PC1 between the CESM POGA ensemble mean and observations. The SOI time series is not superimposed. 
1940s (Fig. A3a). This result is consistent with CM2.1 POGA, further suggesting that the internal variability in the PDO partly contributes to the 1940s regime shift.

\section{REFERENCES}

Alexander, M. A., I. Bladé, M. Newman, J. Lanzante, N.-C. Lau, and J. D. Scott, 2002: The atmospheric bridge: The influence of ENSO teleconnections on air-sea interaction over the global oceans. J. Climate, 15, 2205-2231, https://doi.org/10.1175/ 1520-0442(2002)015<2205:TABTIO > 2.0.CO;2.

An, S.-I., and B. Wang, 2005: The forced and intrinsic lowfrequency modes in the North Pacific. J. Climate, 18, 876885, https://doi.org/10.1175/JCLI-3298.1.

Barlow, M., S. Nigam, and E. H. Berbery, 2001: ENSO, Pacific decadal variability, and U.S. summertime precipitation, drought, and stream flow. J. Climate, 14, 2105-2128, https://doi.org/ 10.1175/1520-0442(2001)014<2105:EPDVAU>2.0.CO;2.

Barnston, A. G., and R. E. Livezey, 1987: Classification, seasonality and persistence of low-frequency atmospheric circulation patterns. Mon. Wea. Rev., 115, 1083-1126, https://doi.org/ 10.1175/1520-0493(1987)115<1083:CSAPOL>2.0.CO;2.

Chen, X., and J. M. Wallace, 2015: ENSO-like variability: 1900 2013. J. Climate, 28, 9623-9641, https://doi.org/10.1175/ JCLI-D-15-0322.1.

Delworth, T., and Coauthors, 2006: GFDL's CM2 global coupled climate models. Part I: Formulation and simulation characteristics. J. Climate, 19, 643-674, https://doi.org/10.1175/ JCLI3629.1.

Deser, C., R. Guo, and F. Lehner, 2017: The relative contributions of tropical Pacific sea surface temperatures and atmospheric internal variability to the recent global warming hiatus. Geophys. Res. Lett., 44, 7945-7954, https://doi.org/10.1002/ 2017GL074273.

Di Lorenzo, E., G. Liguori, N. Schneider, J. C. Furtado, B. T. Anderson, and M. A. Alexander, 2015: ENSO and meridional modes: A null hypothesis for Pacific climate variability. Geophys. Res. Lett., 42, 9440-9448, https://doi.org/10.1002/ 2015 GL066281.

Frankignoul, C., and K. Hasselmann, 1977: Stochastic climate models. Part II: Application to sea-surface temperature anomalies and thermocline variability. Tellus, 29A, 289-305, https://doi.org/10.1111/j.2153-3490.1977.tb00740.x.

Henley, B. J., J. Gergis, D. J. Karoly, S. B. Power, J. Kennedy, and C. K. Folland, 2015: A tripole index for the interdecadal Pacific oscillation. Climate Dyn., 45, 3077-3090, https://doi.org/ 10.1007/s00382-015-2525-1.

Horel, J., and J. Wallace, 1981: Planetary-scale atmospheric phenomena associated with the Southern Oscillation. Mon. Wea. Rev., 109, 813-829, https://doi.org/10.1175/1520-0493(1981)109<0813: PSAPAW $>2.0 . \mathrm{CO} ; 2$.

Huang, B., and Coauthors, 2017: Extended Reconstructed Sea Surface Temperature, version 5 (ERSSTv5): Upgrades, validations, and intercomparisons. J. Climate, 30, 8179-8205, https://doi.org/10.1175/JCLI-D-16-0836.1.

Karoly, D. J., 1989: Southern Hemisphere circulation features associated with El Niño-Southern Oscillation events. J. Climate, 2, 1239-1252, https://doi.org/10.1175/1520-0442(1989)002<1239: SHCFAW $>2.0 . \mathrm{CO} ; 2$.

Kirtman, B. P., and J. Shukla, 2002: Interactive coupled ensemble: A new coupling strategy for CGCMs. Geophys. Res. Lett., 29, 1367, https://doi.org/10.1029/2002GL014834.
Kosaka, Y., and S.-P. Xie, 2013: Recent global-warming hiatus tied to equatorial Pacific surface cooling. Nature, 501, 403-407, https://doi.org/10.1038/nature12534.

$\longrightarrow$, and _ 2016: The tropical Pacific as a key pacemaker of the variable rates of global warming. Nat. Geosci., 9, 669-673, https://doi.org/10.1038/ngeo2770.

Luo, J.-J., and T. Yamagata, 2001: Long-term El Niño-Southern Oscillation (ENSO)-like variation with special emphasis on the South Pacific. J. Geophys. Res., 106, 22 211-22 227, https:// doi.org/10.1029/2000JC000471.

Ma, J., S.-P. Xie, and H. Xu, 2017: Contributions of the North Pacific meridional mode to ensemble spread of ENSO prediction. J. Climate, 30, 9167-9181, https://doi.org/10.1175/ JCLI-D-17-0182.1.

Ma, X., and Coauthors, 2016: Western boundary currents regulated by interaction between ocean eddies and the atmosphere Nature, 535, 533-537, https://doi.org/10.1038/nature18640.

Mantua, N. J., and S. R. Hare, 2002: The Pacific decadal oscillation. J. Oceanogr., 58, 35-44, https://doi.org/10.1023/A:1015820616384. - Y. Zhang, J. M. Wallace, and R. C. Francis, 1997: A Pacific interdecadal climate oscillation with impacts on salmon production. Bull. Amer. Meteor. Soc., 78, 1069-1079, https:// doi.org/10.1175/1520-0477(1997)078<1069:APICOW>2.0. $\mathrm{CO} ; 2$.

Miller, A. J., and N. Schneider, 2000: Interdecadal climate regime dynamics in the North Pacific Ocean: Theories, observations and ecosystem impacts. Prog. Oceanogr., 47, 355-379, https:// doi.org/10.1016/S0079-6611(00)00044-6.

Minobe, S., 1997: A 50-70 year climatic oscillation over the North Pacific and North America. Geophys. Res. Lett., 24, 683-686, https://doi.org/10.1029/97GL00504.

, 1999: Resonance in bidecadal and pentadecadal climate oscillations over the North Pacific: Role in climatic regime shifts. Geophys. Res. Lett., 26, 855-858, https://doi.org/10.1029/ 1999GL900119.

Mo, K. C., and M. Ghil, 1987: Statistics and dynamics of persistent anomalies. J. Atmos. Sci., 44, 877-902, https://doi.org/10.1175/ 1520-0469(1987)044<0877:SADOPA > 2.0.CO;2.

Nakamura, H., G. Lin, and T. Yamagata, 1997: Decadal climate variability in the North Pacific during the recent decades. Bull. Amer. Meteor. Soc., 78, 2215-2225, https://doi.org/10.1175/ 1520-0477(1997)078<2215:DCVITN $>2.0$. CO;2.

Newman, M., and Coauthors, 2016: The Pacific decadal oscillation, revisited. J. Climate, 29, 4399-4427, https://doi.org/10.1175/ JCLI-D-15-0508.1.

—- G. Compo, and M. Alexander, 2003: ENSO-forced variability of the Pacific decadal oscillation. J. Climate, 16 , 3853-3857, https://doi.org/10.1175/1520-0442(2003)016<3853 EVOTPD $>2.0 . \mathrm{CO} ; 2$

Nitta, T., and S. Yamada, 1989: Recent warming of tropical sea surface temperature and its relationship to the Northern Hemisphere circulation. J. Meteor. Soc. Japan, 67, 375-383, https://doi.org/10.2151/jmsj1965.67.3_375.

Nonaka, M., H. Nakamura, Y. Tanimoto, T. Kagimoto, and H. Sasaki, 2006: Decadal variability in the Kuroshio-Oyashio Extension simulated in an eddy-resolving OGCM. J. Climate, 19, 1970-1989, https://doi.org/10.1175/JCLI3793.1.

Okumura, Y. M., 2013: Origins of tropical Pacific decadal variability: Role of stochastic atmospheric forcing from the South Pacific. J. Climate, 26, 9791-9796, https://doi.org/10.1175/ JCLI-D-13-00448.1.

Power, S., T. Casey, C. Folland, A. Colman, and V. Mehta, 1999: Inter-decadal modulation of the impact of ENSO on 
Australia. Climate Dyn., 15, 319-324, https://doi.org/ $10.1007 / \mathrm{s} 003820050284$.

Schneider, N., and B. D. Cornuelle, 2005: The forcing of the Pacific decadal oscillation. J. Climate, 18, 4355-4373, https://doi.org/ 10.1175/JCLI3527.1.

Shakun, J. D., and J. Shaman, 2009: Tropical origins of North and South Pacific decadal variability. Geophys. Res. Lett., 36, L19711, https://doi.org/10.1029/2009GL040313.

Simmons, A. J., J. M. Wallace, and G. Branstator, 1983: Barotropic wave propagation and instability, and atmospheric teleconnection patterns. J. Atmos. Sci., 40, 1363-1392, https://doi.org/ 10.1175/1520-0469(1983)040<1363:BWPAIA > 2.0.CO;2.

Thompson, D., and J. Wallace, 1998: The Arctic Oscillation signature in the wintertime geopotential height and temperature fields. Geophys. Res. Lett., 25, 1297-1300, https://doi.org/ 10.1029/98GL00950.

— lation. Part I: Month-to-month variability. J. Climate, 13, 1000-1016, https://doi.org/10.1175/1520-0442(2000)013<1000: AMITEC $>2.0 . \mathrm{CO} ; 2$

_ J. J. Kennedy, J. M. Wallace, and P. D. Jones, 2008: A large discontinuity in the mid-twentieth century in observed globalmean surface temperature. Nature, 453, 646-649, https://doi.org/ 10.1038/nature06982.

Trenberth, K. E., 1984: Signal versus noise in the Southern Oscillation. Mon. Wea. Rev., 112, 326-332, https://doi.org/10.1175/ 1520-0493(1984)112<0326:SVNITS $>2.0$.CO;2.

—, G. W. Branstator, D. Karoly, A. Kumar, N. Lau, and C. Ropelewski, 1998: Progress during TOGA in understanding and modeling global teleconnections associated with tropical sea surface temperatures. J. Geophys. Res., 103, 14 291-14 324, https://doi.org/10.1029/97JC01444.

Vimont, D. J., D. S. Battisti, and A. C. Hirst, 2001: Footprinting: A seasonal connection between the tropics and mid-latitudes.
Geophys. Res. Lett., 28, 3923-3926, https://doi.org/10.1029/ $2001 \mathrm{GL} 013435$.

—_, J. M. Wallace, and D. S. Battisti, 2003: The seasonal footprinting mechanism in the Pacific: Implications for ENSO. J. Climate, 16, 2668-2675, https://doi.org/10.1175/ 1520-0442(2003)016<2668:TSFMIT >2.0.CO;2.

Wallace, J. M., and D. S. Gutzler, 1981: Teleconnections in the geopotential height field during the Northern Hemisphere winter. Mon. Wea. Rev., 109, 784-812, https://doi.org/10.1175/ 1520-0493(1981)109<0784:TITGHF>2.0.CO;2.

— and D. W. J. Thompson, 2002: The Pacific center of action of the Northern Hemisphere annular mode: Real or artifact? J. Climate, 15, 1987-1991, https://doi.org/10.1175/1520-0442(2002)015<1987: TPCOAO $>2.0 . \mathrm{CO} ; 2$

Wang, H., A. Kumar, W. Wang, and Y. Xue, 2012: Influence of ENSO on Pacific decadal variability: An analysis based on the NCEP Climate Forecast System. J. Climate, 25, 6136-6151, https://doi.org/10.1175/JCLI-D-11-00573.1.

Yeh, S. W., B. P. Kirtman, and S.-I. An, 2007: Local versus nonlocal atmospheric weather noise and the North Pacific SST variability. Geophys. Res. Lett., 34, L14706, https://doi.org/ 10.1029/2007GL030206.

Zhang, L., and T. L. Delworth, 2015: Analysis of the characteristics and mechanisms of the Pacific decadal oscillation in a suite of coupled models from the Geophysical Fluid Dynamics Laboratory. J. Climate, 28, 7678-7701, https://doi.org/10.1175/ JCLI-D-14-00647.1.

Zhang, Y., J. M. Wallace, and N. Iwasaka, 1996: Is climate variability over the North Pacific a linear response to ENSO? J. Climate, 9 , 1468-1478, https://doi.org/10.1175/1520-0442(1996)009<1468: ICVOTN $>2.0 . \mathrm{CO} ; 2$.

,,- , and D. S. Battisti, 1997: ENSO-like interdecadal variability: 1900-93. J. Climate, 10, 1004-1020, https://doi.org/ 10.1175/1520-0442(1997)010<1004:ELIV>2.0.CO;2. 